\title{
PLAYABLE PERSONAS: USING GAMES AND PLAY TO EXPAND THE REPERTOIRE OF LEARNER PERSONAS
}

\author{
Deborah Cole utrecht University, Andrea Maragliano university of Genoa \\ AND Stefan WeRning Utrecht University
}

\begin{abstract}
This article explores how playing and co-creating games in higher education contexts contribute to expanding learner personas and facilitating a multimodal learning experience. Working from the interdisciplinary perspectives of media/games studies, pedagogy, and linguistic anthropology, we conceptualize inclass learning as the making and playing of games, reporting on game experiments and playful practices targeted at learning key theoretical concepts in our disciplines. Game-based modifications to established educational practices involved: replacing lectures with Educational Live Action Role Play (Bowman 2014) sessions, using acting/performance games (Flanagan 2009) to critically reflect on ideas of community and collective identity, and introducing Twine (Werning 2017; Wilson \& Saklofske 2019) to defamiliarize the expected structures and media modalities of academia. Based on evidence from participant reflections and classroom ethnographies, we argue that games can serve as a resource for extending the expressive spectrum of learner personas, for enabling embodied, participatory learning of theory, and for empowering students and educators to reflect on our internalized rules of the game of education.
\end{abstract}

\section{KEY WORDS}

Learner Personas; Playful Identity Performance; Game-Based Learning; Game-Making; Live Action Roleplay

\section{INTRODUCTION}

In this article, we demonstrate approaches to teaching and learning theoretical concepts that invite participants to embody multiple personas while participating in the 'game' of education. In these approaches, learning occurs via explicitly playing and co-creating games followed by reflections on the epistemic implications of critical practice. We begin with a short narrative that articulates the important differences for our study between the traditional game of education and the games we introduced into our classes. This is followed by an overview of theoretical concepts that frame our teaching methods and analysis. We then describe three case studies in which we used games and game-making to teach common but often elusive concepts in the humanities, and help students achieve learning goals by expanding their persona repertoires through embodied in-game performance. 


\section{Defining ‘Playable’ Learner Personas}

Students are socialised into the rules, requirements, and socially acceptable classroom personas $^{1}$ for playing the 'game' of education starting in elementary school (Phillips 1983). How we typically play the game of education limits the ways students and teachers can use their bodies in space, the range of acceptable interactional routines, text types, and modalities for communication, as well as the possibilities for performing voices, roles, or persona types (Robinson \& Taylor 2007; Cole \& Meadows 2013). The notion of persona in (higher) education has been primarily discussed in relation to teachers with a critical focus rather than using personas as tools to design better learning environments. For instance, Kincheloe (2005) urges teachers to develop a more "reflective persona" (p.155) via autoethnographic inquiry. Lang (2007) emphasises the importance of continuity between character archetype and day-to-day behaviour and the rhetorical implications of clothing and outward appearance in "crafting a teaching persona". In contrast, learner personas have received considerably less scholarly attention (see Lilley et al. 2012); a gap this article hopes to address.

One reference point for our definition of 'playable personas' is Werning (2017) on how game creators curate the personas they choose to express themselves through procedural rhetoric in autobiographical games. Accordingly, the player characters in autobiographical games like Depression Quest ${ }^{2}$, represented by the (inter)actions they can and cannot perform, define a spectrum of potential interpretations of the creator's in-game persona. Simultaneously, by constraining the player's potential actions within the game, they also act as 'templates' for players to act out their own identities towards the computer - as these games are usually singleplayer affairs - thereby requiring the player to reassess which personas they usually rely on are compatible with the procedural rhetoric of the game. This definition differs from the notion of "play-personas" (Canossa \& Drachen 2009, p. 513), which are defined as tools for interaction design. It also differs from the more traditional understanding of persona as a character archetype or "part" as in Goffman's (1956, p. 10) notion of identity performance, which Waskul and Lust (2011) utilise in their analysis of negotiating identities in fantasy role-playing games. Waskul and Lust do not explicitly define their notion of persona, but they refer to the "personplayer-persona trinity", specifically the "permeable boundaries between person, player, and persona" in fantasy role-play (2011, p. 340). This interdependence is particularly visible in fantasy contexts, since it is congruent with the "more general trinity of reality, imagination, and fantasy", but according to the authors, the "same porous distinctions and active negotiations also occur in everyday life" (Waskul \& Lust 2011, p. 340) such as educational situations.

A second important reference point is Richard Bartle's (2005) extended player typology, which differentiates between reasons and motivations for playing games. ${ }^{3}$ Bartle's original four types - killers, achievers, explorers, and socialiser - are primarily defined by the player's orientation towards the game and other players. The types added in the extended model, including politicians, hackers, and scientists (Bartle 2005 p.5), are more reminiscent of character archetypes and defined by a relatively consensual set of traits and idiosyncrasies. Bartle's player types refer to distinct motivations and 'playing styles', yet they are functionally comparable to personas, because they, explicitly or implicitly, act as frameworks according to which people interpret their 'expression of self' through play. In the case studies below, we will demonstrate how player personas allow for variation in learner experiences. Furthermore, the cases show how "classroom ecolog[ies]" (Morgan and Martin 2014, p. 669) and game ecologies are co-dependent: games transform the experience of the classroom, and the spatial affordances of the classroom - or, in one case, a theatre room - inform the experience of the game and the performance of classroom personas. Most importantly, we argue that games and game co- 
creation can afford the expression of multiple personas not typically 'permitted' in the classroom.

When we enter a classroom ecology, which operates according to the familiar, internalised rules of traditional classrooms, we tend to take on familiar teacher or student personas. These personas are the social units in which we enact identities (Cole and Meadows 2013), moving in and out of different contexts and interacting with different people in our various communities of practice. In what follows we show that playing a game as a constitutive practice of the classroom promotes a sense of an alternative community among the players by producing shared experiences that lead to an emergent, consensual set of values, habitualised actions, and expanded persona repertoires.

\section{LEARNER PERSONAS AND EMBODIED LEARNING}

Another notion needed to articulate our concept of persona is embodiment. Actually involving the body in learning processes is still often considered experimental, and is rarely implemented as structured classroom practice, as educators perpetuate the discursive separation of theory and practice as well as body and mind (Nelson 2006). Thus, to facilitate learning, we habitually "sit quietly and concentrate on our 'mental' task(s)" (Macedonia 2019, p. 2). Even when we try to increase the body's relevance in our teaching and learning practices, it is hard to let it even partially replace the symbolic system of words, as we cannot fully accept that in embodied teaching and learning "the outcomes might not be further articulated in another mode of cognition such as words, spoken or in writing" (Nelson 2006, p. 106). Despite extensive academic work on embracing "body knowledge" (Maturana \& Varela 1984), current emerging interest in embodiment is due to the advent of neuroscientific studies. Educational and neuropsychological research has shown that when knowledge is linked to emotion, we keep it in our memory longer and more meaningfully (Erk et al. 2003). Such studies have contributed to the "embodied cognition" idea, i.e. an incorporated mind or a mentalised body, wherein "the enactment of knowledge and concepts" happens "through the activity of our bodies" (Lindgren \& Johnson-Glenberg 2013, p. 445). They have also demonstrated how the body's sensorimotor systems (Mahon and Hickok 2016) influence our neuronal processes, memory, and knowledge management. Indeed, several studies have demonstrated how information is connected to words or emotions and also to space, music, faces, flavours, and scent (see, for example, Pulvermüller 2005). When we teach or learn anything, our brains do not only represent and store information via words, but they create and store mind representation via ears, eyes, skin, nose, tongue, and motor acts. Learning involves transforming ourselves, and by virtue of neuroplasticity, our body is constantly mapping new neurological pathways (Blakeslee \& Blakeslee 2007 p. 11). Education practices, however, are rarely multimodal or body-centred, generating a gap between how we acquire and store knowledge, and how we usually frame what we are doing when teaching and acquiring knowledge.

Thompson (2010) argues that body and mind are working together in learning, drawing on conceptual connections between science and art as well as reality and imagination. Munro (2018) builds on this, proposing a list of key features that can be applied to embodied learning contexts, including personal uniqueness, organic congruences, sensory awareness, continuous change, habitual patterns, and re-patterning. Such key features can be used to frame how we think about learning. For example, "organic congruences" which refers to the fact that despite many differences, human beings share similarities on all levels, entails the need to consider the organic and materialistic implications (including socio-cultural influences) in any teaching and learning process. Embodied learning frameworks envision the learning experience as a process of "bodyminded consciousness" wherein "the personal inner environment (the sentient self) as 
well as the multi-layered outer environment" work together "multimodally and often simultaneously" (Munro 2018, p. 10). Thus, embodied learning frameworks assume the learner persona as undergoing "continuous change". Teaching and learning are always multimodal processes made by shifting positions, paradigms, frames, and perspective points; this 'shifting frames of references' attitude is one of the key reasons why games can support educational purposes. Being in a playful mode constantly entails enacting a persona, i.e. any game requires a specific body attitude, gesture movements, and physical interactions, be it a mouse click in a video game or a character posture in a Live Action Role-Playing game (LARP). We show below how including games as multimodal practices in our curricula can support higher education by enabling embodied learning that facilitates students to play multiple personas in safe, exploratory, and communal learning spaces.

\section{CAse STUdies}

To illustrate how games and play may afford a broader range of learner personas in humanitiesbased classrooms, we have chosen an exploratory approach across three scenarios, which can be used as blueprints that can be adapted to other educational contexts. The various game exercises we used in our classes target different "multimodal perceptions, contributing to the embodied consciousness" (Munro 2018, p. 10): scenario A focuses on speaking as an embodied activity, both individually and in various group constellations, scenario B on movement, and scenario $\mathrm{C}$ on writing and collaborative media-making. Playing their game roles and interacting through these modalities, participants are given the opportunity and presented with the necessity to perform other personas within the ecology of the game. After emerging from the game's ecology and back into the wider space of the classroom ecology, participants then reflect on their experiences and make connections to the rules and relevant concepts operating in the larger classroom ecology. Here they return to interacting using their classroom personas, but with the shared, embodied knowledge of their game personas as reference points.

\section{Scenario A: Embodied theory, classroom communities, and expanded personas in a course on language and identity}

When seen through the lens of linguistic theory, personas are linked to the repertoires of voices students bring to class. These are characterised by different phonetic patterns, sentence structures, and vocabulary items used with different people in different social contexts. As speakers perform these voices in their day-to-day interactions with others, they inhabit different personas, or "characterological figures" that others recognise, or not, based on their own prior experiences with the persona types referenced by the performer's linguistic choices (Agha 2007). Personas are thus inextricably tied to the physical embodiment of language in both its spoken and written forms, although other embodied manifestations of identity and affiliation (such as dress, makeup, demeanour, gesture, and objects in one's possession or on one's person) are, of course, crucial to being able to perform and read these personas successfully (Mendoza-Denton 2008; Cole 2020). Anthropological and linguistic studies of education have focused on voices and their related personas in the classroom as sites for investigating the various inequalities we perpetuate when we play by education's traditional, institutionalised rules. These practices that enforce standardised and nationally-valued language varieties ignore or marginalise the rich range of voices and personas students typically use outside of educational contexts (Denham and Loebek 2010; Juffermans and van der Aa 2013; Cole and Meadows 2013). Our course aims to help students become meta-cognitively aware of these practices, especially since some of them will become English teachers. 
Scenario A took place in an upper-level Bachelor's course called "Language and Identity: Researching and Writing Who We Are" as part of a sociolinguistic-focused specialization in an English Language and Culture degree program. The course's six weekly contact hours are divided into a lecture session in a theatre space, a theory seminar, and a gameplay and practice workshop, each for two hours. The main course goal is that students will be able to articulate and apply theory in linguistic anthropology that explains how we perform, recognise, evaluate, and align our identities in interaction with others. The course culminates in a final performance, created and directed by the students for a larger audience in the theatre space. The other assessments are an oral exam over the key theoretical course concepts, an oral performance in which students perform in a voice other than their own and describe the phonetic differences between the two voices, a learning portfolio presented in the medium of their choice, and a classroom ethnography. Much like the classroom described by Loebenberg (2018) which focused on the use of board games in an anthropology course, this course uses games to provide students with an alternate performance of the classroom environment that, when viewed through an ethnographic lens, invites them to "to break ...from typical knowledge production models in their college classrooms".

The range of activities in the course requires participants to shift roles and responsibilities constantly. Students are invited to inhabit another classroom persona with every assessment and activity: they might choose to play the role of actor/performer, game player, game co-creator, explainer, idea pitcher, director, stage manager, linguist, ethnographer, etc. We play several games in the course (a card game, a role-playing game, acting games, movement games, language games), including Werewolves, a role-playing game in which players are given a secret identity as a werewolf or a villager. Many of the players are also given more specific roles within these broader categories, such as the seer, the witch, the mayor, the lovers, etc. Over a series of "game days", the players must decide as a group to kill off one player per day, the villagers aiming to rid the town of werewolves and the werewolves aiming to clear the town of villagers. Players are never sure until their daily collective decision has been made whether they have killed one of their "own" or one of the "others", and decisions about whom to kill proceed through a dialogue facilitated by the game narrator in which the players make the case that someone deserves or does not deserve to die. Players thus have to perform their assigned personas convincingly to avoid being killed off themselves or to convince others that they do not have the identity they've been assigned and must ensure that the other players sharing their same identity category (werewolf or villager) survive.

We play this game shortly before students take their oral exam on the key theoretical terms in linguistic anthropology for describing language and identity described by Bucholtz and Hall (2004). The game involves the students in a simulation in which they can see these terms at work and make those insights explicit in a post-game reflective discussion. The students are given the responsibility for explaining and running the game (some of them have played it before and others have not), as well as for organising the space to facilitate gameplay. The teacher joins the game as one of the players. After gameplay and throughout the rest of the course, the key theoretical concepts, which include power, agency, performance, and practice, authorisation, de-legitimization, authentication, and denaturalization, are used by the teacher and the students as shared vocabulary for classroom discussions as well as for analytical constructs in the rest of the course assessments and learning reflections.

Themes that emerged in student reflections include how games facilitated the learning of theory, how playing inspired community building and trust, and how play encouraged their willingness to take on new classroom personas. Across the board, students were able to accurately and precisely articulate and apply core theoretical concepts, incorporating 
disciplinary jargon naturally and un-self-consciously. In what follows, those instances where students used the theoretical concepts explicitly taught in the course in their own writing, are italicized. ${ }^{4}$

Students articulated their experiences of the embodied, emotional aspects of learning that playing games in class made them aware of. One student, Renske, wrote about how playing games made her "more open toward the information I was trying to learn, and it made it easier to remember". She could "enjoy the games without worrying about learning" and then process what she learned later by talking it over with others. Included in her portfolio is a photograph of the Werewolf role cards, which served as boundary objects for the game, because they activated "fond memories playing werewolves with friends or family, so I really enjoyed playing it in class. It helped me be more at ease around my classmates, as well as helping me in understanding the theory." Here we can see an explicit awareness of the affective aspects of learning as well as the ability to articulate links across the classroom, game, and life space ecologies.

Students also realised how the games we played in class facilitated community building and used theoretical concepts to talk about this. Bram wrote "Werewolves proved an excellent showcase in roles and power relations within the game ... Moreover, there appeared to be a game-transcending trend of trust." Games-playing made students aware that they were taking on different roles in the ecology of the classroom. Ward noted, "We are performing everything we have learnt during the course...on the basis of games and interacting... But we were all assigned (or chose) a role, where we had to act in a way we would not in a regular classroom setting..... Further, the communities of practice these mini-ecologies opened up allowed students to get comfortable taking on other personas within the classroom contexts, which in turn prepared them for taking on other more challenging personas outside of the games themselves. Ymke makes this clear in the following extended passage:

My masterpiece was the role I took during the final performance. It was the first time I had voluntarily taken such a public role. I also learned... how to, somewhat accurately, perform the voice of John Mulaney... Although you, as a reader, may not know this, presentations of any kind have always been the thing I dreaded most in my university career. This course changed that. Although I will not claim that I no longer get nervous for presentations, I have found that I actually like speaking in front of an audience. This became clear when I actually volunteered to be one of the presentation hosts for the performance. It was the first time I voluntarily took a spotlight role. I am proud that I took this role and was able to perform the part of a presenter, because I never expected myself to do something like that.

The final performance in the theatre was an important learning experience for many students who found performing a non-student persona for an audience of their peers and teachers to be a particularly challenging "hurdle". Emma, who stepped out of her comfort zone to take on a directing role writes, "The performance itself taught me how useful it is to use games and activities in order to showcase learning material." Tessa K. writes about how "changing the role of teacher and student" during the performance gave her confidence and taught her "that an examination can be a positive experience, namely one of sharing knowledge in order to teach others as opposed to getting judged for your knowledge or lack thereof." Students gained a meta-cognitive awareness that their habitual roles and practices within an educational context can be repatterned through the embodied experience of taking on other personas. Roos articulates this by applying the theoretical concepts mentioned above in reflecting on her role as scriptwriter: "I noticed a clear development in my understanding of my own identity or, as I 
should say, identities. I have learned that what feels like taking on different 'roles' is actually performing different identities. The fact that I did not struggle with taking on a leader 'role' as much as I used to indicates that performing an identity of a leader has become practice, and thereby one of my identities. Performing an identity that feels unfamiliar, similar to performing a voice or accent that is not your own, can be familiarised and become practice."

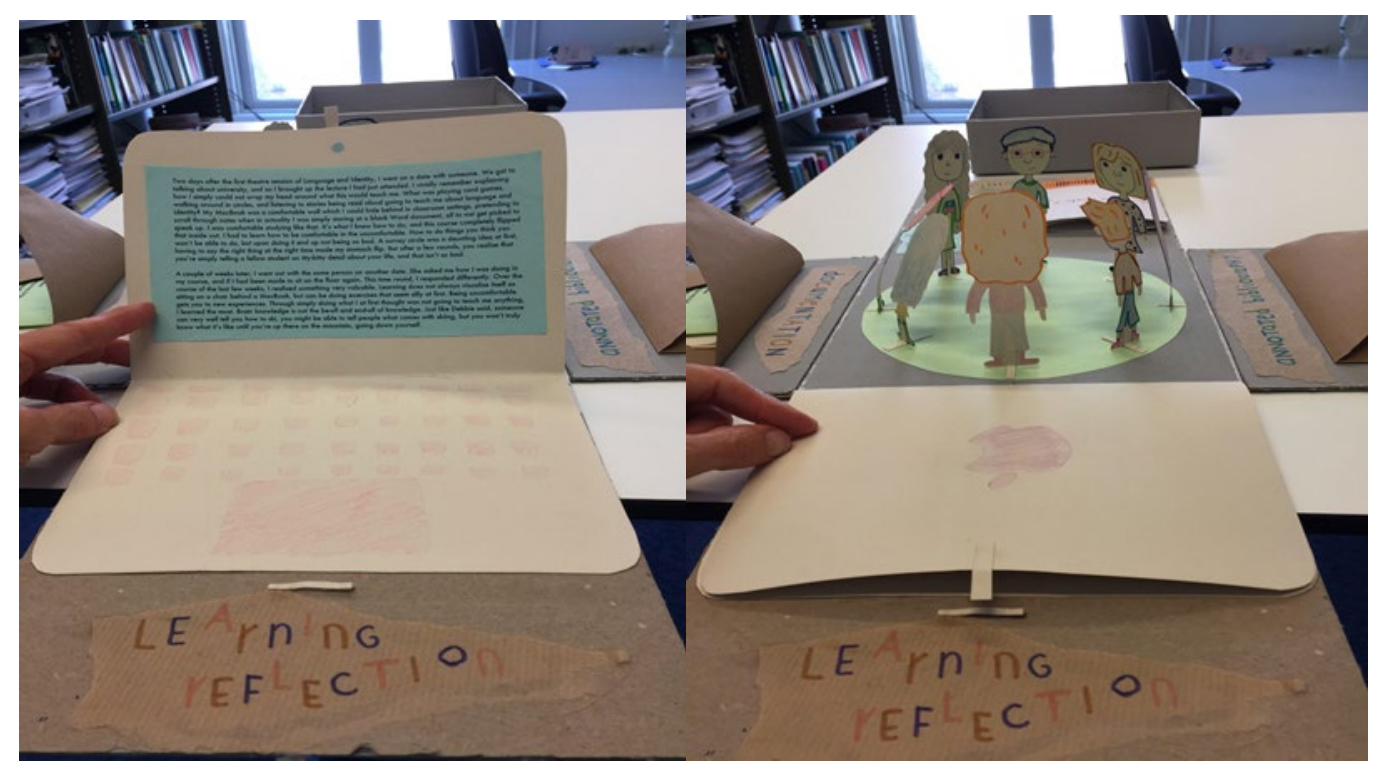

Figure 1. Tessa K's learning portfolio

A clear example that itself embodies the connection between embodied practice and learning and performs connections across the lifeworld game, and classroom ecologies can be seen in Tessa K's learning portfolio (Fig. 1) - a pop-up box she designed in which the learning reflection is pasted onto the screen of a paper laptop. Tessa explains how sitting behind the screen was her preferred mode of learning when she arrived in the course and how she remembers discussing with a friend after the first week that she did not understand how playing games in a theatre could be learning. When you close the laptop, you find you are looking at paper cut-outs of human figures standing upright in a circle. This circle represents our weekly playful opening ritual in the theatre space of going around in a circle taking turns answering a question that anyone in the course could pose to the rest of us. Many students cited this as being the key component in forging a sense of course community. Tessa explains that "exercises that seem silly at first... get you to new experiences... Through simply doing what I at first thought was not going to teach me anything, I learned the most."

\section{Scenario B: Experiencing migrant life stories through an Edu-Live Action Role- Play (LARP)}

Hold The Line is an educative live action role playing game (Bowman 2014) about the Italian refugee's reception system, designed in collaboration with the Italian Red Cross ${ }^{5}$. The game was first created for the social workers of Red Cross migrants and then further adapted to formal and non-formal education contexts: "MeetER", Youth Track Camp (110 participants), "Italian Philosophy Festival" (180 participants) and University of Genoa \& LUISS University of Rome students (50 participants). The game was based on real migrant life stories ${ }^{6}$ and co-designed with migrant social workers and lawyers. Participants play a character who is seeking asylum in Italy, and choose their life path by making narrative choices according to game mechanics inspired by choose-your-own-adventure (CYOA) books. The game choices have to respect the story and the dynamics described in the character sheet, but players have a wide range of 
agency in acting in the game. The game setting comprises three rooms scattered with numbered game cards. Participants follow their asylum-seeking story plot through cards, and for each card they have to make an "in character" choice. Narrative choices concern: legality, health, work, community, reception system, and housing conditions. Each decision on these topics brings participants to a specific numbered card which contains the continuation of their story, which constantly changes based on participants' decisions and actions. Thus, participants find themselves compulsively looking for the next card, room by room, and choice by choice. Occasionally, a choice might allow participants to reminisce, to interact with NPCs (game facilitators in the role of border officers and moneylenders), to assume particular attitudes for a while, or to experience the passing of the time in the "time room" (Fig. 2).
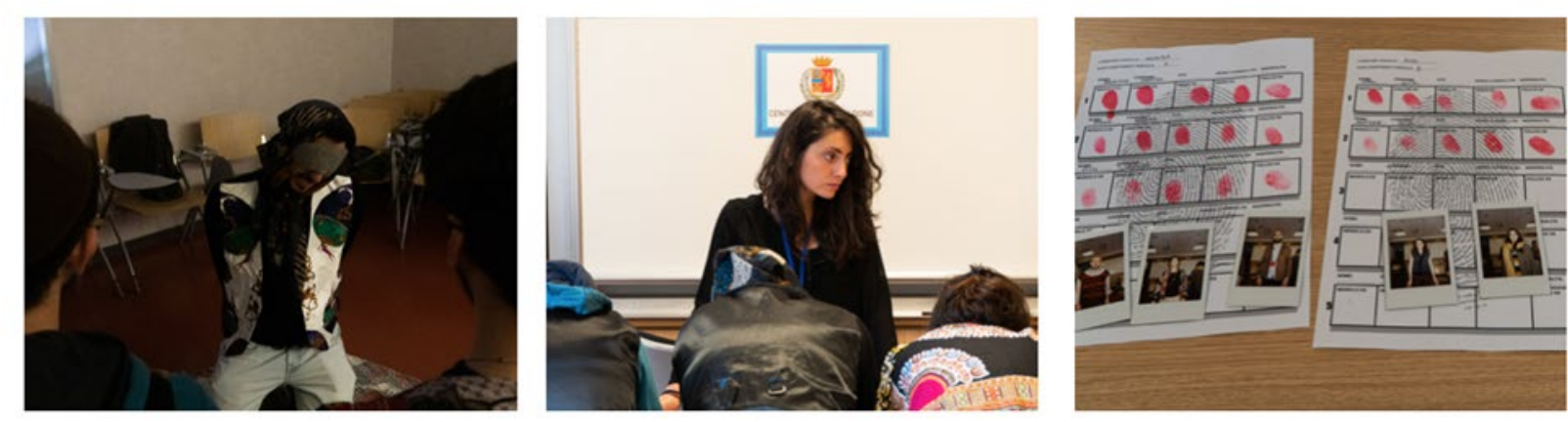

Figure 2: Playing Hold the Line

The fieldwork research conducted to design the game highlighted three recurring keywords, on which the edu-larp (educational live action role play) was designed: choosing, waiting, and barriers. The key concept "choosing" is related to how the institutionalised power structures in the reception system are perceived by migrants, who report constant agency deprivation. The game addresses this concept with the illusory freedom of CYOA game mechanics and the card search representing the migrant bureaucratic legal system. The second key concept, "waiting", relates to how the system forces people to be stuck in limbo in which you can only wait for office appointments, paper permissions, court interviews, and other common requirements for migrants. Hold The Line represents this with the "time room" mechanic; whenever participants choose anything which makes them wait, or if they go to jail, they must go to the time room. Once in the room, they have to kneel, wear a sleeping mask and use earplugs for sensory deprivation. Depending on what they are waiting for, they have to set a timer and wait until the timer rings. Meanwhile, participants cannot move, speak, or do anything. They have to wait, which seems more intense with the sensory reduction? ${ }^{7}$.

Participants may visit the time room repeatedly throughout the game, depending on the story stream they create with their own choices.

The last key game feature was the "barriers" experience. Barriers represent the extensive set of privilege lacking and inequality experiences embedded in refugees' life stories. Participants have to face language, economic, and service access barriers throughout the game. Each barrier is highlighted by an embodied experience. For example, when players interact with officers they have to deal with other languages (Swahili and Fulani language) and have to use body language to express what they want to say. To give players money, lenders will ask for some personal objects in return: an earring, a shoe, an object they had from their home-place, anything to let the players experience the sense of being forced to lose part of their persona to be accepted into the arrival society. If the player's persona becomes unwell and cannot pay to cure themselves, they have to continue the game with ties around their legs to signify physical stress. The game leverages bodily sensations and interactive storytelling to combine the 
cognitive knowledge we have of migrants' experiences with the affective, bodily, and discursive knowledge in a multimodal way.

The game lasts five hours including workshop and debriefing. At the end of the game, participants discover whether they were granted humanitarian protection. They can read the real ending of the real stories they played and a brief overview of the migrant law system schema and FAQs to match what they experienced in the game with the real-life space.

By playing Hold The Line, participants have to perform different personas, playing different roles in gender, cultural background, age, language, life-story, and more. Players have to embody and act out their character in another fictional world that communicates with the daily life world, extending their own personal persona's physical and non-physical repertoire.

During the first game sessions, a research design was set to test the game's effectiveness and receive feedback to improve the game itself. Following an iterative critical design (Flanagan 2009 , p. 257), the game was play-tested with diverse stakeholders (students, migration workers, and refugees), and we invited people with different cultural or life backgrounds to play and offer adjustments. Participants filled in a questionnaire before and after the game, and the debriefing report was also an important way to include participant voices (Lankoski \& Bjork 2015 ) in the game process. Despite research showing how games firmly influence participants' perspective-taking and ethnic prejudice (Maragliano, 2019), scales or measures cannot describe how participant personas transform due to the game. This is why the game effect was discussed through the participants' own descriptions of their experience to try to interpret and highlight the transformative aspects of playing games (Salen \& Zimmerman 2004). The reported findings are taken from the pre-post game survey and debriefing report.

Before and after players participated in the game, we collected their understanding of in-game topics through a free association word stimuli technique via a questionnaire. The word cloud on the left features participant representations before the game, while the one the right (Figure 3) demonstrates their responses post-game. The words in the first cloud can be interpreted as a compassion-driven approach, which depicts migrants as resourceless and poor, thus perpetuating conventionalised and well-meaning but often harmful forms of representation (Leonardo 2002). After the game, there is a clear shift of labelling. 'The' migrant is now characterised with words like understanding, reflection, people and courage. Following the game, migrant personas are not primarily regarded as a 'problem to solve', but rather as people to understand, with experiences worthy of more nuanced reflection.
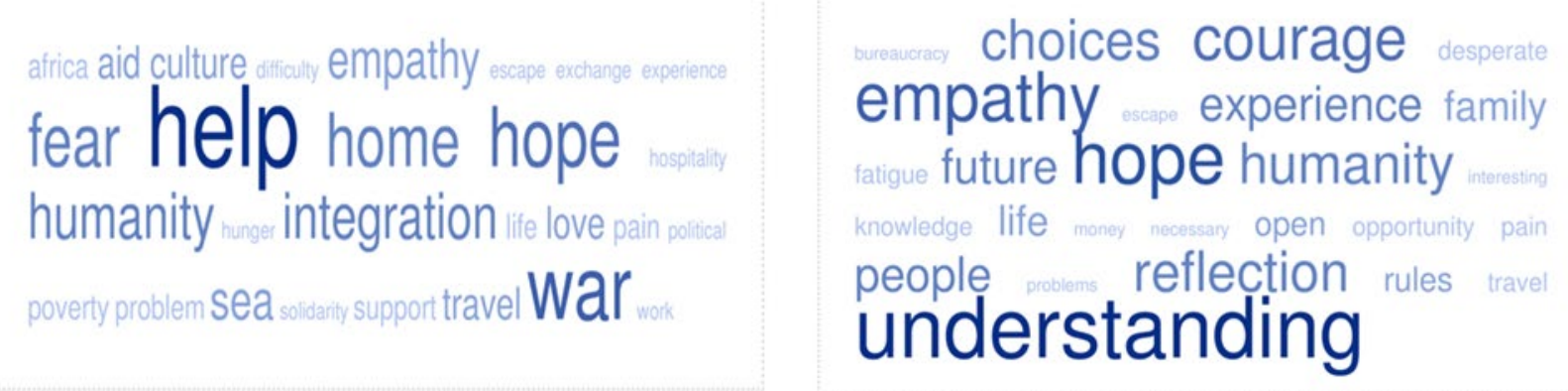

Figure 3. Pre-game and post-game word clouds reflecting keywords associated with migrants

Further debriefing and a player survey demonstrated a willingness to change after the game experience. The following quotations provide an overview of player reflection in this regard: 
S.19: "A game that makes you better understand what migrants have to face since they touch Italian land. I would like to get even closer to this reality and bring my contribution, maybe do volunteer work in this field!".

S. 32: "From now on I'm going to try harder to look at people reflecting on their hands, their signs, their scars, their stories, their efforts".

The following excerpt is peculiar because it was from a student who worked in migrant rehabilitation, reflecting on knowledge and practice involved in her workplace.

S.02: "I realized, in a role-reverse way, how the talk "bear with me" I always say to migrants I work with really makes me feel. When it comes to paperwork, lawyers, anything, I always tell them "be patient, come on." When in the game I was told to be patient after I had been in the time room 3 times I would have killed the NPC."

Finally, students reflect on their own multimodal experiences, such as perceptions of time, which they felt allowed them to more easily empathise with 'the migrant' as personas, incorporating the migrants' stories more naturally into their own in-class identity performance.

S: 08: "A really useful activity to make it clear that a migrants' journey does not end when they arrive in Italy. But it continues for years. I never expected to discover the waiting time they may have during the journey and the obstacles to overcome, and then maybe discover that they are not accepted. It should not be taken for granted that just because there are directives there are safe procedures with clear timescales.".

\section{S. 13: "I thought about the difficulty with which foreigners on the run are} welcomed in Italy or not. The expectations and all the unforeseen events are nerve-wracking, and we have lived them ONLY for three hours and I couldn't take it anymore, this is everyday life for some people."

S. 21: "I work in a shelter, and I always have to deal with these documents. But I had never filled the refugee application form all by myself before, it was hard for me too, and it is written in my language."

Naturally, the above quotations are simply statements about intention, but it is particularly interesting that players link their character persona experienced throughout the game with their own real-life persona. Their reflections reinforce the idea that embodying knowledge transformation more easily leads to a bodily action transformation. These quotations suggest that 'knowing' something and 'experiencing' it - if only in the context of make-believe situations that exhibit the characteristic ambiguity (Sutton-Smith 2006) of play but are nonetheless informed by real migrants' life stories - produces different learning outcomes than purely rational approaches.

\section{Scenario C: Experimenting with learner personas through game-making}

The third scenario explores how the theory of embodying and expanding the expressive spectrum of learner personas can be fostered through game-making. The corresponding exercises took place in two advanced Bachelor of Art courses, the aforementioned "Language and Identity" and a media studies course called "Speelse Communicatie" [Playful Communication]. The latter group comprised of eleven teams of two to four students, each tasked with creating a small-scale persuasive game within four weeks. Participants' study backgrounds included media, communication, and culture studies, with different specialisations such as media history, media design, gender studies, or screen-based media like television and 
cinema. Due to the focus on persuasive communication and most students not possessing technical backgrounds, the authoring tool Twine was chosen as a common basis for all student games. In previous research, Twine has already been identified as a tool that affords selfreflexivity, especially in questions of identity politics. For instance, Bragança et al. (2016) show how Twine has been used to not only explore queer identities or, more broadly, the complications of non-binary identity formation through interactive narratives, but also allow the game creators an opportunity to reflect on and push against the limited spectrum of 'acceptable' creator personas within the digital games industry.

In academic contexts, Wilson and Saklofske (2019) argue that Twine has the potential to "challenge [the] often-exclusive scholarly methods and communication strategies" (p.4) that characterise both research and education. Wilson and Saklofske (2019) do not explicitly reference learner personas, but several of their key claims and examples suggest that the tool's disruptive potential stems in part from expanding the notion of learner personas. Academic use of Twine allows for "constellating ideas, and anticipating narrative networks and multiple pathways through such ideas" (2019, p. 4); that is, due to its quick and iterative applicability, the tool allows users to experiment with multiple viewpoints and 'roles' rather than to claim and defend one. Furthermore, Wilson and Saklofske (2019) argue that "Twine creations occupy a liminal space between multiple media forms and the expectations of gaming, literary, and filmic cultures of production and consumption" (p. 4). Thus, using Twine encourages students to draw from a broader range of personal experiences than they would in more traditional classroom ecologies. For example, one student game studies "the relationship between William Blake's creative process, his biographical context, and his prophetic works" (Wilson and Saklofske 2019 , p. 6). Rather than presenting their findings as an 'external' observer, the student's game characteristically emulates Blake's viewpoint, making the author the protagonist of the game. The game harnesses the "person-player-persona trinity" (Waskul and Lust 2004, p. 340) to afford both its creator and players an 'embodied' experience of William Blake's life and work as well as address historiographical ambiguities.

The learning goals for the game-making exercise at hand were to a) understand how playful communication strategies are developed in a 'dialogue' with the tools and materials used; b), to explore the notion of bricolage in research (Antonijevic and Cahoy 2018); and c), to 'translate' a shared personal experience into an in-game persona. Procedural rhetoric in selected student games was evaluated (Colby 2014) based on the prototypes and corresponding reflection notes to identify patterns in the use and transformation of learner personas throughout the process. The student games covered a broad range of topics from the ecological footprint of tourism and 'fast fashion', and issues of inequality (e.g. concerning the situation of immigrants or the homeless in the Netherlands), to personal experiences like connecting with relatives who have Alzheimer's disease or coping with the loss of loved ones.

A central concern in all projects was the 'creator' persona; making media rather than 'just' reflecting on them was a novel experience for many students. The reflection notes indicate that many considered the creative task epistemically different from traditional notions of scholarly work. Nelson emphasises that modes of scholarship like "writing or rhetorical debate [...] are themselves practices" (2006, p.108), which often appear counterintuitive within traditional classroom ecologies. At the beginning of the course, several students described their role as the 'recipient' of knowledge or skills; in comparison, learning by making a game - much like playing a game - is a process of testing hypotheses and determining 'what works'. Indeed, several reflection notes stated that students also applied this process, which they associate with a 'designerly' approach based on creating and iteratively 'refining' an artifact, to writing their final papers. 
Marshall et al. (2015) briefly discuss game creator persona characteristics using Minecraft creator Marcus 'Notch' Persson as an example (p. 297). While Notch, unlike the course participants, had adopted and committed to the creator persona early on, we observed the characteristic tension between making and playing one's own game also applied to the group experience. Like many independent developers, Notch negotiated the discrepancy between the highly commodified idea of commercial games in mainstream culture (and the expectations coming with that idea), and the desire for self-expression, cultivating an "indie" attitude. Similarly, many (early) designs and reflection notes exhibit concessions towards usability and 'avoiding frustration', reflecting the 'professional developer' persona's perspective on gamemaking. Demonstrating the games at a pitch session towards the end of the course provided a forum for 'acting out' different interpretations of the creator persona; in future iterations, this 'stage' for enacting personas should be expanded on. Many students initially responded to the unfamiliar design exercise by 'retreating' into familiar, often gendered personas such as the programmer, the writer, the visual artist or the organiser/manager. By lowering the technical requirements of game-making, Twine allows for gradually merging these otherwise rigid categories. For instance, due to the tool's popularity, sample code for many routine scripting tasks like changing text or background colours upon certain triggers is available online. Even the team's writers could insert into the project without needing to fully understand it, which expanded the expressive qualities of their texts.

On a related note, the retreat into familiar roles meant students would act out their primary "player types" (Bartle 2005). For example, competitive-minded students initially approached the game-creation exercise as an opportunity to reassert their superior performance, while others appreciated the exercise as a catalyst to socialise with their peers. The 'explorer' type would manifest itself in the form of students experimenting with different techniques and re-framing their own experience to 'translate' it into the game. Achievers would instead aim to combine scripting and formatting to achieve design effects that transcend what Twine can do 'out of the box'. One such technique that two teams explored was to use a variable, a value representing the player character's physical or mental well-being, to change the background colour, reflecting the internal development of the in-game persona. Even though the exercise took place over only four weeks, the pre-existing roles changed and even merged in some cases as students became more familiar with the tool or more immersed in the fictional 'world' they created.

This change demonstrates the interdependence of personas in a classroom ecology; by learning Twine together, dynamic configurations of individual learner personas gradually developed into more well-defined communities of practice. For example, as students realised that Twine does not really afford a highly specialized programmer persona, a more accessible version of that archetype became available to others as well. The success of learning environments and performing group identity "is dependent on the emergence of a shared sense of purpose, capability or practice, a means for engagement, and a shared set of resources" (Benn et al. 2013, p. 187). In that context, the acquisition of specialised knowledge, which distinguished the group from their cohort, and which many had deemed outside the scope of their habitual learner persona beforehand, contributed to the process. As suggested above, the authoring tool Twine and the digital prototypes themselves constitute important "stage props" in a Goffmanian (1956, p. 13) sense that students incorporated into their performance of learner personas. Having to express themselves using Twine's limited technical features, but also being able to combine media modalities like typography, colour, images, film clips, maps and more, helped students develop an awareness of their own disciplinary boundaries but also find ways to move past them in order to create a coherent persuasive game. One way to harness this more systematically in future iterations of the exercise will be to have student teams re- 
write earlier groups' anonymised prototypes. This affords students an embodied engagement with the personas expressed by their peers not just through 'reading' but also 'writing'.

A distinct challenge in all projects was to write an in-game persona for the players to inhabit collectively. The game-maker-as-persona already requires epistemic flexibility because, to make a game, one needs to empathise with different viewpoints and provide meaningful choices for different player types (Bartle 2005) rather than fully identifying with any one of them.

During the creation of the prototypes, students needed to identify and negotiate different versions of the in-game persona they tried to create within the team. For example, the team behind the game Road to Happiness, which addresses the experience of a refugee in the Netherlands, combined their personal anecdotal experiences into an in-game persona, e.g. by distributing them as micro-narratives across different branching paths or dialogue responses.

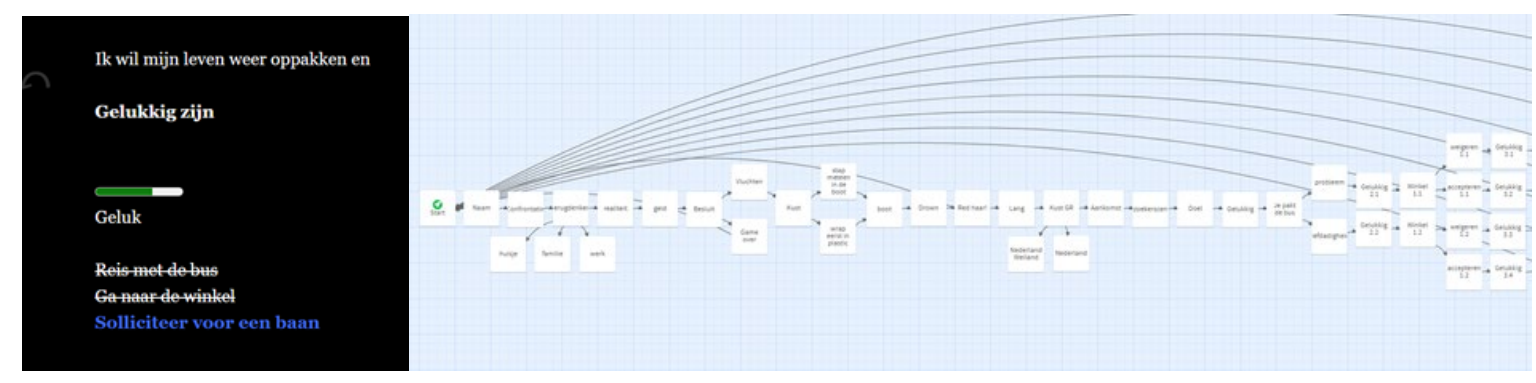

Figure 4. Screenshot and story structure of the Road to Happiness prototype

The game Dress to Impress, which critically engages with the moral quandaries surrounding fast fashion, implies but never explicates a male lower-middle-class student as the central player persona. However, it complicates this seemingly clear-cut persona by repeatedly and abruptly shifting the viewpoint, including a friend of the protagonist, an extra-diegetic narrator, and a girl working in a Bangladeshi factory that produces fashion products.

\section{CONCLUSION}

The game-creation exercises described here allow for educators to better understand and tentatively expand the spectrum of learner personas, and to make the classroom a 'play space' experienceable by the students. However, to deliver on its promise, a more long-term perspective is necessary. Goffman (1956) already started his analysis of the presentation of self in everyday life, including higher education, by acknowledging the "belief in the part one is playing" (1956, p. 10), that is how (learner) personas are internalised over time. Thus, it is necessary to provide multiple opportunities within a curriculum to actualise and flesh out these alternative performances of the self. Despite referring to very different educational formats and media modalities, the three scenarios exhibit several thematic and conceptual similarities. All three describe social learning situations in which the appropriative quality of play (Sicart 2014) gradually enabled students to experiment with different learner personas. More recently, teaching classes from home within the COVID-19 pandemic restrictions since 2020 has been posing new challenges and opportunities in that regard. It makes education appear all the more game-like because, as McLuhan (1994) argues, "when the social rules change suddenly, then previously accepted social manners and rituals may suddenly assume the stark outlines and the arbitrary patterns of a game" (1994, p. 238-39). In that context, online education intensifies the hybridisation of classroom and everyday personas, which makes the identity politics inherent in playing the education game particularly evident. 
We conclude by briefly addressing two methodological considerations. First, to complement the exploratory approaches presented in this article, a more systematic ethnographic investigation of one particular group would be useful to unpack the highly idiosyncratic play experiences and motivations in the classroom. Second, we urge educators to consider games as critical practices rather than ready-to-hand 'tools', choosing a timeframe appropriate for the learning goals and context. It takes time for a persona to become more than 'playing a part', and to widen the epistemic horizon of students, allowing them to draw on a broader range of personal experiences in the acquisition and processing of knowledge.

\section{END NOTES}

1. The term "classroom persona" is not always consistently define, but usually refers to educators; for example, Cook (2009) uses it (283) interchangeably with related terms like "teacher persona" (282).

2. See http://www.depressionquest.com/.

3. Bartle's is but one of many player typologies; see e.g. Tuunanen, J \& Hamari, J 2012. For this study, however, it is the most relevant one due to its evocative categories and attention to players changing 'types' over time.

4. Students in the course were asked for informed consent to use their course work in our research on play and learning and were consulted as to whether or not they wanted to be cited as the author of their work in published research. Examples presented here are cited from their learning portfolios and reflection forms after the final performance.

5. The live and online versions of the game were designed by Andrea Maragliano, Martina Vertuccio, Federica Pinato, Samuele Nava, andSofia Moriconi (Italian Red Cross).

6. The playable roles are composed of 17 stories, for a total of 42 characters from: Afghanistan, Angola, Bangladesh, Cameroon, Ivory Coast, Eritrea, Gambia, Rojava Kurdistan-Syria, Nigeria, Pakistan, Senegal, Syria, Somalia, Ukrainian/RPD, and Venezuela. Each character is given a "historical memory" explaining the historical context, current political situation, and migration factors; a "group memory" containing the character's family context; and an "individual memory" that tells the story of the individual character.

7. Players' safety is always respected: the mechanic is explained during the game briefing and participants can quit the game whenever they want by saying the safe word.

\section{WORKS CITED}

Agha, A 2007, Language and Social Relations. Cambridge, Cambridge University Press.

Antonijevic, S \& Cahoy, ES 2018, 'Researcher as Bricoleur: Contextualizing humanists' digital workflows', Digital Humanities Quarterly, vol. 12, no. 3, retrieved from <http://www.digitalhumanities.org/dhq/vol/12/3/000399/000399.html>.

Bartle, R 2005, 'Virtual Worlds: Why People Play', in T Alexander (ed), Massively Multiplayer Game Development Vol. 2, Hingham, MA, Charles River Media, pp. 3-18. 
Benn, S, Edwards, M \& Angus-Leppan, T 2013, 'Organizational Learning and the Sustainability Community of Practice: The Role of Boundary Objects', Organization and Environment, vol. 26, no. 2, pp. 184-202.

Blakeslee, S \& Blakeslee, M 2007, The body has a mind of its own: how body maps in your brain help you do (almost) everything better. New York, Random House.

Bowman, SL 2014, Educational live action role-playing games: A secondary literature review. The Wyrd Con Companion Book, pp. 112-131.

Bragança, L, Mota, R \& Fantini, E 2016, 'Twine Game Narrative and discussion about LGBTQ representation' in XV SBGames, Sao Paulo, pp. 937-946, retrieved from <http://www.sbgames.org/sbgames2016/downloads/anais/157380.pdf>.

Bucholtz, M. \& Hall, K 2004, 'Language and identity' in A Duranti (ed.) A Companion to Linguistic Anthropology, Oxford: Blackwell, pp. 369-394.

Canossa, A \& Drachen, A 2009, 'Play-personas: Behaviours and belief systems in user-centred game design' in T Gross, J Gulliksen, P Kotzé, L Oestreicher, P Palanque, RO Prates, \& M Winckler (eds.) Proceedings of the 12th IFIP TC 13 International Conference, Berlin \& Heidelberg, Springer, pp. 510-523.

Colby, R 2014, 'Writing and assessing procedural rhetoric in student-produced video games' Computers and Composition vol. 31, pp. 43-52.

Cole, D 2020, 'The emergent selectivity of semiotically playful utterances' in Contact Talk: The Discursive Organization of Contact and Boundaries. London, Routledge.

Cole, D \& Meadows, B 2013, 'Re-imagining sociolinguistic identification in foreign language classroom communities of practice' in D Rivers \& S Houghton (eds.) Social Identities and Multiple Selves in Foreign Language Education, London, Continuum.

Cook, Jennifer S 2009, 'Coming Into My Own as a Teacher: Identity, Disequilibrium, and the First Year of Teaching' New Educator, vol. 5 no. 4, pp. 274-92.

Denham K \& Lobeck A (eds.) 2010, Linguistics at School: Language Awareness in Primary and Secondary Education, Cambridge University Press, Cambridge.

Erk, S, Kiefer, M, Grothe, J, Wunderlich, AP, Spitzer, M \& Walter, H 2003, Emotional context modulates subsequent memory effect. Neuroimage, vol. 18, pp. 439-447.

Flanagan, M 2009, Critical play: Radical game design. Cambridge, MA, MIT press.

Goffman, E 1956, The Presentation of Self in Everyday Life. Edinburgh, University of Edinburgh Social Sciences Research Centre.

Lankoski, P \& Björk, S 2015, Game research methods: An overview. Pittsburgh, PA, ETC Press.

Juffermans, K and Van der Aa, J 2013, Introduction to the special Issue: Analyzing voice in educational discourses. Anthropology \& Education Quarterly, vol. 44, no. 2, pp. 112-123.

Kincheloe, J 2005, 'Auto/biography and Critical Ontology: Being a Teacher, Developing a Reflective Teacher Persona', in WM Roth (ed.) Auto/Biography and Auto/Ethnography. Rotterdam: Sense Publishers, pp. 155-174.

Lang, J M 2007, 'Crafting a teaching persona', The Chronicle of Higher Education, vol. 53, no. 23, retrieved from: <https://www.chronicle.com/article/crafting-a-teaching-persona/>.

Leonardo, Z 2002, 'The souls of white folk: Critical pedagogy, whiteness studies, and globalization discourse', Race ethnicity and education, vol. 5, no. 1, pp. 29-50.

Lilley, M, Pyper, A \& Attwood, S 2012, 'Understanding the Student Experience through the Use of Personas', Innovation in Teaching and Learning in Information and Computer Sciences, vol. 11, no. 1, pp. 4-13.

Lindgren, R \& Johnson-Glenberg, M 2013, 'Emboldened by embodiment: six precepts for research on embodied learning and mixed reality', Educational Researcher, vol. 42, no. 8, pp. 445-452.

Loebenberg, A 2018, 'Sneak Attack Anthropology: Experiences with Games in the College Classroom', Analog Game Studies, vol. 5, no. 2, retrieved from <http://analoggamestudies.org/2018/06/sneak-attack-anthropology-experienceswith-games-in-the-college-classroom/>.

Macedonia, M 2019, Embodied Learning: Why at School the Mind Needs the Body. Frontiers in Psychology, vol. 10, pp. 1-8. 
Mahon, B Z \& Hickok, G 2016, 'Arguments about the nature of concepts: symbols, embodiment, and beyond.' Psychonomic Bulletin \& Review, vol. 23, pp. 941-958.

Maragliano, A 2019, 'Edu-larp Paths in Education: A Pedagogic Research on Ethnic Prejudice and Empathy through Games', 9th International Conference the Future of Education.

McLuhan, M 1994. Understanding Media: The Extensions of Man, Cambridge, MA, MIT Press.

Mendoza-Denton, N 2008, Homegirls: Language and cultural practice among Latina youth gangs. Malden, MA, Blackwell Publishing.

Morgan, B \& Martin, I 2014, 'Toward a research agenda for classroom-as-ecosystem.' The Modern Language Journal, vol. 98, no. 2, pp. 667-670.

Munro, M 2018, 'Principles for embodied learning approaches', South African Theatre Journal, vol. 31, no. 1, pp. 5-14.

Nelson, R 2006, 'Practice-as-research and the problem of knowledge', Performance Research: A Journal of the Performing Arts, vol. 11, no. 4, pp. 105-116.

Philips, S. 1983, The Invisible Culture: Communication in Classroom and Community on the Warm Springs Indian Reservation, Broadway, NY, Longman.

Pulvermüller, F. 2005, 'Brain mechanisms linking language and action.' Nature Reviews Neuroscience, vol. 6, pp. 576-582.

Robinson, C \& Taylor, C 2007. 'Theorizing student voice: Values and perspectives'. Improving schools, vol. 10, no. 1, pp. 5-17.

Salen, K \& Zimmerman, E 2004, Rules of Play: Game Design Fundamentals, Cambridge, MA, MIT Press.

Sicart, M 2014. Play Matters, Cambridge, MA, MIT Press.

Sutton-Smith, B 2006. 'Play and Ambiguity', in K Salen \& E Zimmerman (eds.) The Game Design Reader: A Rules of Play Anthology. Cambridge, MA: MIT Press, pp. 296-313.

Waskul, D \& Lust, M 2004, 'Role-Playing and Playing Roles: The Person, Player, and Persona in Fantasy Role-Playing', Symbolic Interaction, vol. 27, no. 3, pp. 333-356.

Thompson, E. 2010. Mind in life. Cambridge, MA: Harvard University Press.

Tuunanen, J \& Hamari, J 2012, 'Meta-synthesis of player typologies', in Proceedings of Nordic Digra 2012 Conference: Local and Global - Games in Culture and Society, retrieved from <http://www.digra.org/wp-content/uploads/digital-library/12168.40312.pdf>.

Werning, S 2017, 'The persona in autobiographical game-making as a playful performance of the self', Persona Studies, vol. 3, no. 1, pp. 28-42.

Wilson, R \& Saklofske, J 2019, 'Playful Lenses: Using Twine to Facilitate Open Social Scholarship through Game-based Inquiry, Research, and Scholarly Communication', Knowledge Creation, Dissemination, and Preservation Studies, vol. 3, no. 1, retrieved from <http://kula.uvic.ca/articles/10.5334/kula.11/>. 